\title{
Alterations in Central Neuropeptide Expression, Release, and Receptor Binding in Rats Bred for High Anxiety: Critical Role of Vasopressin
}

\author{
Alexandra Wigger*,', Mar M Sánchez², Kenneth C Mathys², Karl Ebner ${ }^{3}$, Elisabeth Frank', Dong Liu', \\ Adelheid Kresse ${ }^{4}$, Inga D Neumann ${ }^{5}$, Florian Holsboer', Paul M Plotsky', Rainer Landgraf' \\ 'Max Planck Institute of Psychiatry, Behavioural Neuroendocrinology, Munich, Germany; '²mory University School of Medicine, Atlanta, USA; \\ ${ }^{3}$ University of Innsbruck, Innsbruck, Austria; ${ }^{4}$ Karl-Franzens-University Graz, Graz, Austria; ${ }^{5}$ University of Regensburg, Regensburg, Germany
}

\begin{abstract}
To model aspects of trait anxiety/depression, Wistar rats were bred for extremes in either hyper (HAB)- or hypo(LAB)-anxiety as measured on the elevated plus-maze and in a variety of additional behavioral tests. Similar to psychiatric patients, HAB rats prefer passive stress-coping strategies, indicative of depression-like behavior, show hyper-reactivity of the hypothalamo-pituitary-adrenal axis, and a pathological response to the dexamethasone/corticotropin-releasing hormone $(\mathrm{CRH})$ challenge test. Here we tested central mRNA expression, release patterns, and receptor binding of neuropeptides critically involved in the regulation of both anxiety-related behavior and the HPA axis. Thus, $\mathrm{CRH}$, arginine-8-vasopressin (AVP), and oxytocin (OXT) were studied in brains of HAB and LAB males both under basal conditions and after exposure to a mild emotional stressor. In HAB rats, CRH mRNA was decreased in the bed nucleus of the stria terminalis only. While no significant difference in $\mathrm{CRHI}$-receptor binding was found in any brain area, $\mathrm{CRH} 2$-receptor binding was elevated in the hypothalamic paraventricular nucleus (PVN), the ventromedial hypothalamus, and the central amygdala of HABs compared to LABs. AVP, but not OXT, mRNA expression as well as release of the neuropeptide, were higher in the PVN of HABs, whereas AVP VI a-receptor binding failed to show significant differences in any brain region studied. Remarkably, intra-PVN treatment of HABs with the AVP VI-receptor antagonist d $\left(\mathrm{CH}_{2}\right)_{5} \operatorname{Tyr}(\mathrm{Me}) \mathrm{AVP}$ resulted in a decrease in anxiety/depression-related behavior. The elevated expression and release of AVP within the PVN of HAB rats together with the behavioral effects of the AVP $V I$-receptor antagonist suggest a critical involvement of this neuropeptide in neuroendocrine and behavioral phenomena associated with trait anxiety/ depression.

Neuropsychopharmacology (2004) 29, I - |4, advance online publication, 27 August 2003; doi: I 0. I 038/sj.npp. I 300290
\end{abstract}

Keywords: AVP; CRH; oxytocin; HAB; microdialysis; emotionality

\section{INTRODUCTION}

In clinical therapy of anxiety disorders and depression, mostly incidentally or empirically detected substances are applied that may show a variety of undesirable side effects. Therefore, a deeper knowledge of the neurobiological mechanisms underlying normal and pathological emotionality may result in improved therapeutic approaches. Since humans suffering from psychiatric disorders are not easily accessible for neurobiological studies, several animal models have been developed to mimic psychopathological conditions (Overstreet et al, 1992; Driscoll et al, 1998; Escorihuela et al, 1999). Over the past few decades, two

\footnotetext{
*Correspondence: Dr A Wigger, Max Planck Institute of Psychiatry, Kraepelinstr. 2, D 80804 Munich, Germany, Tel: + 498930622 228, Fax: + 498930622 569, E-mail: Wigger@mpipsykl.mpg.de

Received 04 March 2003; revised 10 June 2003; accepted I 5 July 2003 Online publication: 21 July 2003 at http://www.acnp.org/citations/ NPP072 $10303093 /$ default.pdf
}

Wistar rat lines have been bred in our laboratory for extremes in high (HAB) or low (LAB) anxiety-related behavior on the elevated plus-maze (EPM) and were now established as a novel animal model of trait anxiety/ depression (for a review, see Landgraf and Wigger, 2002, 2003).

In a variety of additional behavioral tests, $\mathrm{HAB}$ rats showed indices of hyper-emotionality, hyper-reactivity, and passive stress-coping strategies indicative of depression-like behavior (Liebsch et al, 1998a, b; Henniger et al, 2000; Ohl et al, 2001; Wigger et al, 2001; Keck et al, 2002), whereas LABs were hypo-anxious and preferred active stress-coping strategies. This behavioral divergence could be reproduced in different laboratories by different experimentors and was thus shown to be a consistent and robust trait (Salomé et al, 2002). Treatment of HABs with anxiolytic (diazepam, Liebsch et al, 1998b) or antidepressive (paroxetine, Keck et al, 2003) drugs resulted in a pronounced reduction in anxiety-related and depression-like symptoms, respectively, thus providing pharmacological validation of the animal 
model. It may, thus, serve as a useful tool for studying the role of central neuromodulators and neurotransmitters in regulating behavioral as well as neuroendocrine parameters associated with trait anxiety/depression.

One of the main neuroendocrine systems suggested to be critically involved in anxiety/depression-related behavior is the hypothalamic-pituitary-adrenocortical (HPA) axis, well known to be activated by exposure to emotional and/or physical stressors (Plotsky, 1991; Aguilera, 1994). The release of corticotropin-releasing hormone (CRH) and arginine-8vasopressin (AVP) from neurons of the paraventricular hypothalamic nucleus (PVN) into the pituitary portal blood triggers the secretion of adrenocorticotropin (ACTH) from the anterior lobe. Subsequently, corticosterone is secreted from the adrenal cortex into blood and, beside its metabolic effects, exerts a negative feedback on HPA axis activity via pituitary, hypothalamic, limbic, and cortical regions (Sapolsky and McEwen, 1985; De Kloet et al, 1991, 1999). Resembling depressive patients (Holsboer, 1989), hyperanxious HAB rats show signs of an elevated HPA axis reactivity upon exposure to a mild emotional stressor (Landgraf et al, 1999) and a pathological outcome of the dexamethasone/CRH test (Keck et al, 2002). Interestingly, the latter may be normalized by peripheral administration of a V1-receptor (R) antagonist suggesting a critical involvement of endogenous AVP in this neuroendocrine aberration linked to anxiety/depression (Keck et al, 2002).

In addition to and independent of its role in neuroendocrine regulation, brain AVP has been described to contribute to the control of anxiety-related behavior. Both transiently decreasing V1a-R expression in the septum using antisense targeting and infusion of a V1-R antagonist decreased anxiety in rats, as measured by increased time spent in the open arm of the EPM (Landgraf et al, 1995a; Liebsch et al, 1996). Consistent with these observations, voles with elevated V1a-R expression in the ventral pallidum exhibited a decrease in time spent in the open arm of the EPM (Pitkow et al, 2001). Similar to AVP, CRH at the level of the brain induces anxiogenic effects (van Gaalen et al, 2002) as part of its complex involvement in stressrelated responses of the organism. Accordingly, treatment with the novel CRH-R1 antagonist R121919 reduced anxiety-related behavior in $\mathrm{HAB}$, but not $\mathrm{LAB}$ animals (Keck et al, 2001). In view of the wide range of CRH and AVP effects on anxiety we hypothesize that - similar to but independent of HPA axis regulation - both neuropeptides in varying ratios may shape behavioral phenomena linked to innate emotionality. Therefore, further investigation of central CRH and AVP systems controlling both anxietyrelated behavior and HPA axis activity is a reasonable approach in the research of the neurobiological basis of physiological and pathological anxiety.

We examined mRNA expression, central release patterns, and receptor binding of CRH and AVP in both $\mathrm{HAB}$ and $\mathrm{LAB}$ rats under basal conditions and after mild emotional (10-min exposure to an open arm of the EPM; Landgraf et al, 1999) or combined emotional and physical (forced swim; Liebsch et al, 1998b; Neumann et al, 1998) stimulation by means of in situ hybridization, in vivo microdialysis, and receptor-binding autoradiography. Additionally, to investigate the functional impact of intra-PVN AVP expression and release in trait anxiety, $\mathrm{HAB}$ rats were infused with an
AVP V1-R antagonist directly into the hypothalamic PVN, and behavioral consequences of the treatment were demonstrated in the EPM and forced swim tests. Similar to $\mathrm{CRH}$ and AVP, the structurally related neuropeptide oxytocin (OXT) was recently reported to contribute to the regulation of both HPA axis activity and emotional behavior (Windle et al, 1997; Neumann et al, 2000a; Bale et al, 2001). These results prompted us to determine OXT mRNA expression and intra-PVN release additionally in the same animals studied for CRH and AVP.

\section{MATERIALS AND METHODS}

\section{Animals}

The animal studies were conducted in accordance with the Guide for the Care and Use of Laboratory Animals of the Government of Bavaria and the guidelines of the NIH.

As described in detail by Landgraf and Wigger (2002), Wistar rats obtained from a commercial supplier (Charles River, Sulzfeld, Germany) were selected using the results from an EPM test and mated to establish the lines termed $\mathrm{HAB}$ and $\mathrm{LAB}$. Both rat lines were treated strictly in parallel in terms of care, mating, and behavioral testing in the animal facility of the Max Planck Institute of Psychiatry in Munich, under standard laboratory conditions $(12: 12 \mathrm{~h}$ light/dark cycle, lights on at $0600,22^{\circ} \mathrm{C}, 60 \%$ humidity, standard rat chow and tap water ad libitum). Data presented in this paper were obtained from male animals from the F9-F12 generations.

\section{Behavioral Tests and Stress Paradigms}

EPM test and open-arm exposure. The EPM test is based on creating a conflict between the rat's exploratory drive and its innate fear of open and exposed areas (Pellow et al, 1985; Liebsch et al, 1998a) and consisted of a plus-shaped platform, lit by a mean light intensity of 100 lux, with two closed (with $40 \mathrm{~cm}$ walls) and two open arms (each $50 \times 10 \mathrm{~cm}^{2}$ ), connected at the center by a neutral zone $\left(10 \times 10 \mathrm{~cm}^{2}\right)$ and elevated $73 \mathrm{~cm}$ above the floor.

The animals, still in their home cages, were transferred to the EPM laboratory at least $16 \mathrm{~h}$ prior to the test that was always carried out between 0800 and 1200. Before the introduction of each rat, the maze was cleaned with water containing a detergent. The animal was then placed onto the central area of the maze, facing a closed arm. During the 5min exposure, the following parameters were recorded by means of a video/computer system (Plus-maze V2.0, Ernst Fricke, Germany, 1993): (i) the number of entries into open and closed arms, (ii) percentage of entries into open arms (ratio of open-arm entries to sum of entries into all arms), (iii) the time spent in both types of arms, (iv) the percentage of time spent on the open arms (ratio of time spent on open arms to total time spent on all arms), and (v) latency to the first entry into an open arm.

When using the maze as a mild emotional stressor (openarm exposure), entries into the neutral zone and the closed arms were blocked during the 10-min exposure.

Forced swim. The rats were placed into a Plexiglas container $(40 \mathrm{~cm}$ diameter, $60 \mathrm{~cm}$ high) filled to a height 
of $50 \mathrm{~cm}$ with $19^{\circ} \mathrm{C}$ tap water. After a 10 -min swim, animals were gently dried with a cloth towel and placed back into their home cage. Durations of swimming, struggling, and floating behavior as well as latency to the first signs of floating were scored by a trained observer blind to treatment using a computer program (Eventlog Event Recorder V1.0, Robert Henderson, Germany, 1986).

\section{Surgeries}

The microdialysis probes (U-shaped, Spectra/Por hollow fiber dialysis membrane, outer diameter $0.25 \mathrm{~mm}, 1.5 \mathrm{~mm}$ length, in vitro recovery of radiolabeled AVP and OXT between 1.6 and $2.0 \%$ ) were implanted under halothane anesthesia (Hoechst, Frankfurt am Main, Germany) 2 days before starting the experiments. Rats were fixed in a stereotaxic frame, the calvaria was exposed, and the microdialysis probe was lowered with its U-shaped tip reaching the right PVN $(1.8 \mathrm{~mm}$ caudal to bregma, $1.6 \mathrm{~mm}$ lateral to midline, $9.2 \mathrm{~mm}$ beneath the surface of the skull with an angle of $10^{\circ}$ to the vertical to avoid damage to the sagittal sinus; Paxinos and Watson, 1998). For antagonist administration, both PVNs were approached by one probe (1.8 $\mathrm{mm}$ caudal to bregma, $3.0 \mathrm{~mm}$ lateral to midline, $9.4 \mathrm{~mm}$ beneath the surface of the skull with an angle of $20^{\circ}$ to the vertical). The microdialysis probe was fixed to the skull, and two jewelers' screws with dental acrylic, and the animals were injected with $0.03 \mathrm{ml}$ of a depot-antibiotic substance (Tardomyoce ${ }^{\circledR}$, Bayer, Leverkusen, Germany). The microdialysis probe was connected to in- and outflow tubing (PE-10, Portex, UK). Following surgery, rats were individually housed in transparent Plexiglas cages $\left(24 \times 31 \times 35 \mathrm{~cm}^{3}\right)$ and handled carefully to familiarize them with the microdialysis sampling and infusion procedures, respectively.

\section{Experimental and Analytical Protocols}

The focus was laid essentially on those brain areas known to be involved in the regulation of both HPA axis and anxiety/ depression-related behavior.

$m R N A$ expression and neuropeptide receptor binding. Male HABs and LABs ( $n=5-7$ per group, 250-300 g) were used either under undisturbed conditions (all studies), $30 \mathrm{~min}$ (CRH-R binding assays) or $2 \mathrm{~h}$ (in situ hybridization for AVP and OXT mRNA) after exposure to a mild emotional stressor ( $10 \mathrm{~min}$ on an open arm of the EPM). The animals were decapitated under short halothane anesthesia, and the removed brains were shock-frozen in dry-ice chilled methylbutane.

CRH mRNA in situ hybridization histochemistry. Radiolabeled rat cRNA probes were used following procedures described previously (Young et al, 1997; Sánchez et al, 1999, 2000). Briefly, sections were fixed in $4 \%$ paraformaldehyde, then acetylated $(0.25 \%$ acetic anhydride in $0.1 \mathrm{M}$ triethanolamine), dehydrated, delipidated, and air-dried. After prehybridization $\left(53^{\circ} \mathrm{C}, 2 \mathrm{~h}\right)$ and drying, hybridization occurred overnight $\left(53^{\circ} \mathrm{C}\right)$ with purified cRNA probes $(0.3 \mu \mathrm{g}$ probe $\times$ length $(\mathrm{kb}) / \mathrm{ml}) .\left[{ }^{35} \mathrm{~S}\right]$-radiolabeled antisense and sense cRNAs were transcribed from a $500 \mathrm{bp}$ cDNA
EcoRI-PvuII fragment subcloned from a $1.2 \mathrm{~kb} E c o R \mathrm{I}$ fragment of a full-length rat CRH cDNA (kindly provided by $\mathrm{Dr} \mathrm{K}$ Mayo, Northwestern University, Evanston, IL). Antisense and sense cRNA probes were synthesized incorporating $\left[{ }^{35} \mathrm{~S}\right] \mathrm{CTP}$ (New England Nuclear, Boston, MA) at a specific activity of $9 \times 10^{8} \mathrm{cpm} / \mu \mathrm{g}$ probe. After several washes, sections were treated with ribonuclease A $(20 \mu \mathrm{g} / \mathrm{ml}$ in RNase buffer) followed by incubation with DTT (1 mM). Finally, sections were again washed, dehydrated, air-dried, and exposed to Kodak BioMax MR film (Eastman Kodak Co., Rochester, NY) along with autoradiographic $\left[{ }^{14} \mathrm{C}\right]$ microscale standards (Amersham Life Science Inc., Arlington Heights, IL) for 5 days at room temperature. Specific CRH mRNA hybridization was determined by comparing the hybridization signal from the antisense with that of the sense cRNA strand probe.

Autoradiograms from the in situ hybridization studies were analyzed using the NIH IMAGE program (http:// rsb.info.gov/nih-image). The mean optical density (OD) was measured in each area of interest and all OD readings were converted into $\mathrm{nCi} / \mathrm{g}$ tissue equivalents by means of standard curves generated using autoradiographic $\left[{ }^{14} \mathrm{C}\right]$ microscale standards.

We quantified four sections per animal per region of interest in both hemispheres. Slides were not emulsion dipped because autoradiograms provide a good measure of CRH mRNA expressed in parvocellular neurons of the PVN without the need for microscopic examination (CRH is not expressed in any other cell type in the PVN).

CRH-R1- and -R2-binding autoradiography. CRH-R1and -R2-binding autoradiography was performed according to procedures previously described (Skelton et al, 2000). Briefly, slide-mounted tissue sections were thawed, fixed in $0.1 \%$ paraformaldehyde, and then preincubated in $50 \mathrm{mM}$ Tris- $\mathrm{HCl}, 10 \mathrm{mM} \mathrm{MgCl}_{2}, 2 \mathrm{mM}$ EGTA. Then, incubation

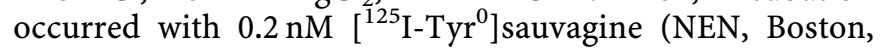
MA; specific activity: $2200 \mathrm{Ci} / \mathrm{mmol}$ ) in $50 \mathrm{mM}$ Tris $-\mathrm{HCl}$, $10 \mathrm{mM} \mathrm{MgCl}_{2}, 2 \mathrm{mM}$ EGTA, $0.1 \%$ bovine serum albumin, aprotinin $(0.04 \mathrm{TIU} / \mathrm{ml})$, and $0.1 \mathrm{mM}$ bacitracin. $\left[{ }^{125} \mathrm{I}-\right.$ $\mathrm{Tyr}^{0}$ ]sauvagine has high affinity for both CRH-R1 $\left(K_{\mathrm{D}}=0.2-0.4 \mathrm{nM}\right)$ and CRH-R2 $\left(K_{\mathrm{D}}=0.1-0.3 \mathrm{nM}\right)$ (Grigoriadis et al, 1996; Primus et al, 1997). Two further sets of adjacent sections were used: in one set, $1 \mu \mathrm{M}$ CP-154,526-1 (butyl-[2,5-dimethyl-7-(2,4,6-trimethylphenyl)-7H-pyrrolo[2,3-d]pyrimidin-4-yl]-ethylamine; kindly provided by $\mathrm{Dr}$ L Martarello, at Emory University, Atlanta, GA), a selective CRH-R1 antagonist, was added to the incubation buffer in order to displace $\left[{ }^{125} \mathrm{I}-\mathrm{Tyr}^{0}\right]$ sauvagine from the CRH-R1 subtype; in the other set of adjacent sections, $1 \mu \mathrm{M}$ unlabeled sauvagine (American Peptide Company, Sunnyvale, GA) was added to the incubation buffer to define nonspecific binding. Following incubation, all sections were washed in PBS (1\% BSA) and air-dried. Autoradiograms from receptor-binding studies were analyzed using the NIH IMAGE program (http://rsb.info.gov/nih-image). All OD readings were converted into $\mathrm{dpm} / \mathrm{mg}$ tissue equivalents by means of standard curves generated using $\left[{ }^{125} \mathrm{I}\right]$ microscale standards.

As described above, three consecutive sets of sections were used for quantification of CRH-R1 and CRH-R2 
binding: (a) sections incubated with $\left[{ }^{125} \mathrm{I}-\mathrm{Tyr}^{0}\right]$ sauvagine, which represent total binding of this ligand to both CRH-R1 and CRH-R2, (b) sections incubated with [ $\left.{ }^{125} \mathrm{I}-\mathrm{Tyr}^{0}\right]$ sauvagine in the presence of $1 \mu \mathrm{M} \mathrm{CP}-154,526-1$, a compound that displaces binding from $\mathrm{CRH}-\mathrm{R} 1$, therefore representing binding to CRH-R2, and (c) sections for nonspecific binding, whose values were subtracted from both sets a and b. Specific CRH-R1 binding was calculated by subtracting the specific CRH-R2 binding from the total $\left[{ }^{125} \mathrm{I}-\mathrm{Tyr}^{0}\right]$ sauvagine binding to both $\mathrm{CRH}-\mathrm{R} 1$ and CRH-R2. An average of five sections were measured in each animal for each region of interest (in both hemispheres) to generate mean binding values. Only values above $2 \times$ standard deviation from nonspecific binding values were considered detectable. Representative images of receptor binding are shown in Figure 1.

AVP and OXT mRNA in situ hybridization histochemistry. Due to the high expression of both AVP and OXT mRNAs in the hypothalamic PVN and SON, we focused on these nuclei; none of the other regions showed detectable expression levels. Not only the PVN but also the SON is known to be involved in both emotionality (Engelmann et al, 1994, 1999) and HPA axis regulation (Wotjak et al, 2002).

Prior to hybridization, slides were dehydrated and air-dried. For hybridization of AVP mRNA, we used a highly specific 48-base-long oligonucleotide directed against the last 16 amino acids of the glycoprotein that AVP does not share with OXT ( $5^{\prime}$ gcagaaggcccogecggeccgtccagctgcgtggcgttgctccggtc; Ivell and Richter, 1984; Villar et al, 1994). OXT mRNA was hybridized by using a similarly

\section{CRH receptor autoradiographs}
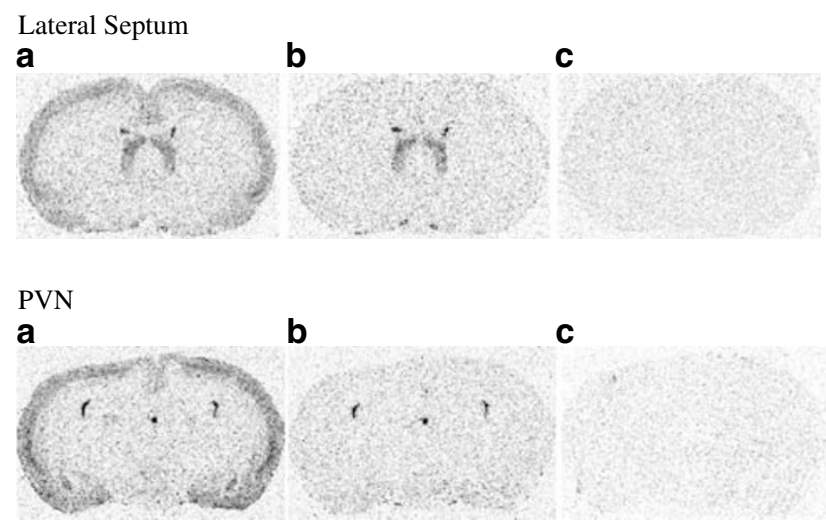

Ventromedial hypothalamus

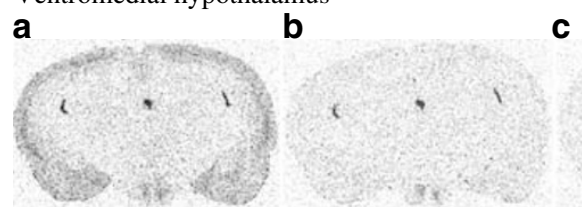

Figure I Representative images of $\mathrm{CRH}$ receptor binding at different levels of the brain (lateral septum, PVN, and ventromedial hypothalamus). From left to right, each column of the sections represents (a) total ${ }^{125} \mathrm{I}$ ]sauvagine binding to both $\mathrm{CRH}-\mathrm{RI}$ and $\mathrm{CRH}-\mathrm{R} 2$, (b) binding to CRFR2 (sections incubated with $\left[{ }^{125} \mid\right]$ sauvagine and the selective CRH-RI antagonist), and (c) nonspecific binding. specific 48 -base long oligonucleotide $\left(5^{\prime}\right.$ ctcggagaaggcagactcagactcagggtcgcaggcggggtcggtgcggcagcc; Ivell and Richter, 1984). The oligonucleotides were labeled using terminal transferase (TdT, Boehringer, Germany) and $\left[{ }^{35} \mathrm{~S}\right] \mathrm{dATP}$ (NEN DuPont, Germany) and purified by t-RNA (Sigma, Germany) precipitation. Incubation occurred in a humid chamber $\left(20 \mathrm{~h}\right.$ at $\left.45^{\circ} \mathrm{C}\right)$ with a radioactivity of $50000 \mathrm{cpm} /$ $100 \mu \mathrm{l} /$ slide. After several washes, slides were dehydrated and air-dried (for detailed description of data analysis, see below).

To check for the specificity of the oligonucleotide hybridization, some sections were preincubated with a 50 fold excess of the cold oligonucleotides before the radioactively labeled probes were added. Under these conditions, no signal was registered within the respective nuclei.

AVP V1a-R binding autoradiography. This analysis was conducted in brain sections from the same $\mathrm{HAB}$ and $\mathrm{LAB}$ males used for AVP and OXT mRNA hybridization following procedures previously described (Young et al, $1999,2000)$. Before incubation, the slides were fixed using $0.1 \%$ paraformaldehyde and washed. For competitive displacement of endogenous AVP and for receptor binding, slides were incubated (60 min, RT) with the AVP V1a-R antagonist ${ }^{125} \mathrm{I}$-lin AVP (NEX310, DuPont NEN, Boston, USA; $200 \mathrm{cpm} / \mu \mathrm{l})$. After several washes, the slides were airdried (for a detailed description of data analysis see below).

Data analysis. In all in situ hybridization and receptorbinding analyses, the sections were exposed to Kodak BioMax or B-max MR films (Eastman Kodak Co., Rochester, NY or Amersham, Germany) for 2-5 days. The radiationinduced blackening of the nuclear films was determined by means of image analysis optical software (NIH IMAGE program; http://rsb.info. gov/nih-image or Optimas 5.2, Optimas Corporation, Germany). Autoradiograms from in situ hybridization and receptor-binding studies for AVP, OXT, and $\mathrm{CRH}$ were analyzed using the OD readings which were then converted into $\mathrm{nCi} / \mathrm{g}$ or $\mathrm{dpm} / \mathrm{mg}$ tissue equivalents by means of standard curves generated using either $\left[{ }^{14} \mathrm{C}\right]$ or $\left[{ }^{125} \mathrm{I}\right]$ microscales (Amersham Life Science Inc., Arlington Heights, USA). An average of three to six matched sections were measured in each animal for each region of interest to generate mean hybridization or binding values.

For $\mathrm{CRH}$, specific mRNA hybridization was determined by comparing the hybridization signal from the antisense with that of the sense cRNA strand probe, and data were adjusted to $\left[{ }^{14} \mathrm{C}\right]$ standards. For CRH-R1 and -R2 autoradiography, the data were adjusted to $\left[{ }^{125} \mathrm{I}\right]$ standards. Specific CRH-R2 binding was obtained by subtracting nonspecific binding from $\left[{ }^{125} \mathrm{I}^{-\mathrm{Tyr}^{0}}\right]$ sauvagine binding in the presence of $1 \mu \mathrm{M}$ CP-154,526-1. Specific CRH-R1 binding was calculated by subtracting nonspecific from the total $\left[{ }^{125} \mathrm{I}-\mathrm{Tyr}^{0}\right]$ sauvagine binding and then subtracting specific CRH-R2 binding.

For AVP and OXT, specific mRNA hybridization and receptor binding, respectively, were determined by comparing the hybridization signal of the studied regions with the background, and data were adjusted to $\left[{ }^{14} \mathrm{C}\right]$ standards. For more detailed analysis of AVP expression on cellular level, slides were dipped in 50\% nuclear emulsion (NTB2, Kodak, 
Germany) and exposed for $48 \mathrm{~h}$. After development and fixation (Kodak, Germany), the slides were slightly counterstained with $1 \%$ cresyl violet and covered. The number of silver grains indicating AVP mRNA expression was counted in parvocellular neurons (20 cells in two sections per animal, identified according to their localization within the PVN, Swanson and Sawchenko, 1983) by an observer blind to the animals' specifications. Spotted magnocellular neurons within the parvocellular part of the PVN, as identified by their size, were excluded.

In vivo microdialysis. At 2 days after surgery, at 0800, the microdialysis probe was connected to the microinfusion pump (TSE, Bad Homburg, Germany) and perfused at a rate of $200 \mu \mathrm{l} / \mathrm{h}$ with sterile Ringer's solution (Fresenius, Germany, $\mathrm{pH}$ 7.4) for $2 \mathrm{~h}$ to establish an equilibrium between inside and outside of the dialysis membrane, while the rats were left undisturbed (for a detailed description, see Neumann et al, 1993; Landgraf et al, 1995b; Wotjak et al, 1996).

Seven consecutive 30 -min microdialysates were collected in Eppendorf tubes, prepared with $10 \mu \mathrm{l}$ of $0.01 \mathrm{~N} \mathrm{HCl}$ (Merck, Germany) and snap-frozen on dry ice immediately after removal from the animal. Following two basal dialysate collections, during ongoing microdialysis, rats were exposed to an open arm of the EPM for $10 \mathrm{~min}$ and then returned into their home cage. After collection of two further dialysates, at the beginning of the sixth sample, the animals were forced to swim for $10 \mathrm{~min}$ while microdialysis continued and, thereafter, one further 'undisturbed' collection was obtained.

After the experiment, a functional control was performed as described by Neumann et al (1993). Briefly, three more consecutive dialysates were collected. During the second dialysis interval, $\mathrm{NaCl}$-hypertonic Ringer's solution (0.7 M) was perfused and only rats that showed a pronounced 'rebound' effect in the third dialysate were included for further analysis. In addition to providing a functional index of probe placement, this test sheds some light on the releasable pool of AVP and OXT within the dialyzed area.

In a further follow-up experiment, again basal and posthypertonic samples were collected and both AVP and OXT release were measured in the same dialysates.

Administration of an AVP V1-R antagonist by inverse microdialysis. For local delivery of a highly selective AVP V1-R antagonist $\left(\mathrm{d}\left(\mathrm{CH}_{2}\right)_{5} \mathrm{Tyr}(\mathrm{Me}) \mathrm{AVP}\right.$, provided by $\mathrm{Dr} \mathrm{M}$ Manning, Toledo, USA), a microdialysis probe was implanted adjacent to both PVNs (Figure 2) 2 days prior to inverse microdialysis. At $30 \mathrm{~min}$ prior to anxiety testing on the EPM, rats were infused (dialysis rate: $200 \mu \mathrm{l} / \mathrm{h}$ ) with either vehicle (sterile Ringer's, $n=9$ ) or AVP V1-R antagonist solution (delivery into the PVNs during a 30min interval ca $5 \mathrm{ng}$, diffusion area approx. $0.5 \mathrm{~mm}^{3}$, Engelmann et al, 1992; $n=8$ ).

Histological verification of the microdialysis probe placement. At the end of the experiments, the microdialyzed animals were killed by an over-dose of halothane. The brains were removed, snap-frozen in dry ice-chilled $N$-methylbutane (Roth, Germany), and stored at $-20^{\circ} \mathrm{C}$ until sectioning with a cryocut (Microm HM 500, Germany).
Cresyl violet-stained coronal sections of the brains $(25 \mu \mathrm{m})$ were used for reconstruction of the placement of the microdialysis probes (example given in Figure 2).

Radioimmunoassays for AVP and OXT. Only successfully implanted rats with (i) the microdialysis probe placed within or adjacent to the hypothalamic nucleus (histology not shown) and (ii) a strong rise in neuropeptide release in response to hypertonic medium were analyzed for neuropeptide release upon stressor exposure.

AVP and OXT contents in the dialysates were estimated in lyophilized samples by sensitive and specific radioimmunoassays (minimal detection limit: $0.03 \mathrm{pg} / \mathrm{sample}$; intra- and interassay variations were between 7 and $10 \%$, and 9 and $13 \%$, respectively). Crossreactivities of the antisera with related peptides (including AVP and OXT, respectively) were $<0.7 \%$ (Landgraf et al, 1995b).

\section{Statistical Analysis}

Data are presented as group means \pm SEM. Statistics were performed by means of computer software (GB-Stat V6.0, Dynamic Microsystems, USA).

mRNA-expression and/or selective receptor binding of $\mathrm{CRH}$ under basal conditions and after stress exposure were statistically analyzed using a Mann-Whitney $U$-test (HAB vs LAB) under separate conditions since they were estimated in two different analytical sets.

Comparisons of $\mathrm{HAB}$ and $\mathrm{LAB}$ males with respect to basal and poststress mRNA expression of AVP and OXT were performed using a randomized two-way ANOVA (factors rat line and treatment). Line differences in AVP V1a-R binding were compared using the Mann-Whitney $U$-test under basal and poststress conditions, respectively.

AVP and OXT contents in microdialysates were calculated using a two-way ANOVA corrected for repeated measures (factors rat line $\times$ time), and in order to note subtle line differences, detailed by using the Mann-Whitney $U$-test for

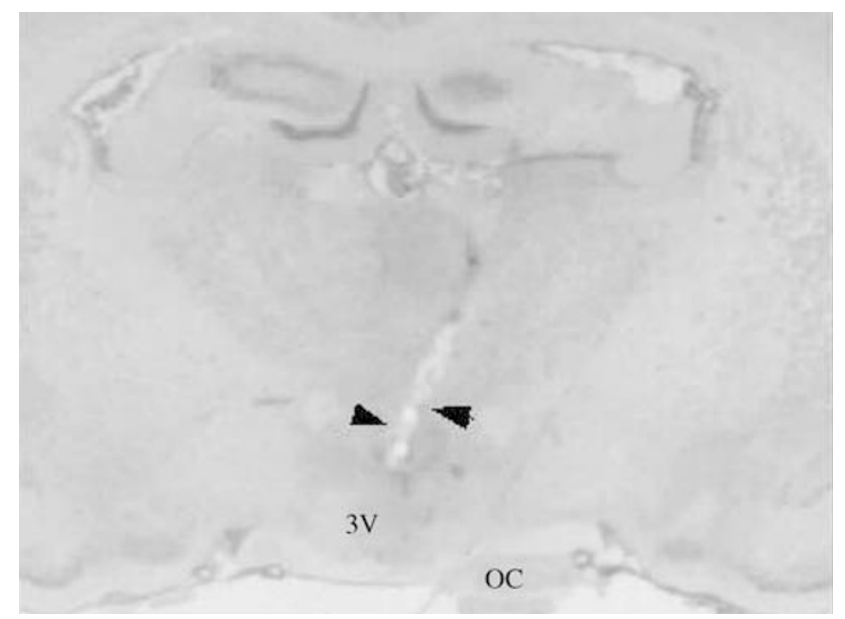

Figure 2 Photomicrograph of a histological preparation $(25 \mu \mathrm{m})$ of the hypothalamic PVN implanted with a microdialysis probe for retrodialytic administration of an AVP VI-R antagonist. The arrowhead points out the remaining lesion after removal of the probe showing the correct placement attaining both PVNs. OC: optic chiasma, 3V: third ventricle. 
basal levels (dialysate 1) and stress-induced release (ratio: swim/preswim, ie dialysates 6/5).

The behavioral data obtained in the EPM and during forced swimming in HABs after microdialysis administration of the AVP V1-R antagonist into the PVN were processed with the Mann-Whitney $U$-test. $p<0.05$ was considered statistically significant.

\section{RESULTS}

\section{Corticotropin-releasing hormone}

Basal mRNA expression of CRH (Table 1, Figure 3a). The basal expression of CRH mRNA was significantly lower in the bed nucleus of the stria terminalis (BNST, $p<0.05 v s$ $\mathrm{LAB})$ and tended to be lower in the central amygdala $(p=0.08 v s$ LAB) of HABs. In the other areas studied, including the PVN (Figure 3a), no line differences were detected.

Basal and poststress CRH-R1 binding (Table 2). In all the brain areas studied, the binding of the selective ligand to

Table I CRH mRNA Expression (OD units) Within Brain Areas in Male HAB and LAB Rats Under Basal Conditions

\begin{tabular}{lccc}
\hline & HAB (n=5) & LAB (n=5) & p-Values \\
\hline PVN & $56.7 \pm 1.07$ & $49.6 \pm 3.03$ & 0.12 \\
BNST & $24.6 \pm 4.34$ & $38.1 \pm 1.60$ & 0.047 \\
Barrington nucleus & $18.0 \pm 3.93$ & $12.9 \pm 2.23$ & 0.60 \\
Central amygdala & $26.2 \pm 5.03$ & $36.5 \pm 2.23$ & 0.08 \\
Raphe nucleus & $13.8 \pm 3.97$ & $12.7 \pm 2.61$ & 0.75 \\
\hline
\end{tabular}

Data are means \pm SEM.

a
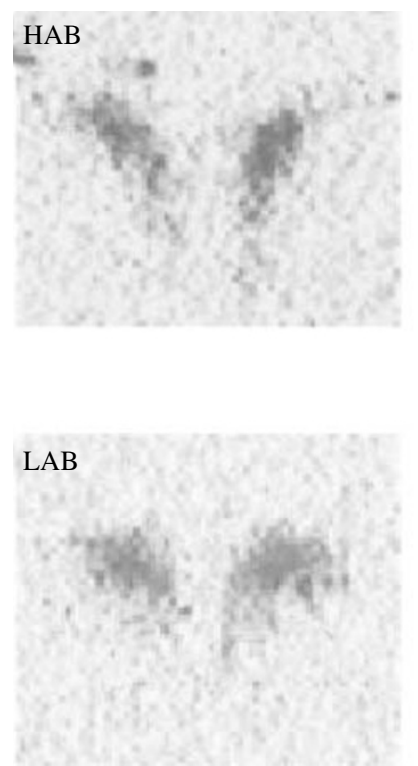

Figure 3 Representative images of (a) $\mathrm{CRH}$ and (b) AVP mRNA expression in the PVN of $H A B$ and $L A B$ rats under basal conditions.
CRH-R1 was similar in both lines either under basal conditions or $30 \mathrm{~min}$ after a 10 -min open-arm exposure. Only in the central amygdala, CRH-R1 binding tended to be reduced in HABs under basal conditions ( $p=0.08 v s \mathrm{LAB})$.

Basal and poststress CRH-R2 binding (Table 3). Selective CRH-R2 binding within the PVN was significantly higher in HABs than in LABs under basal conditions $(p<0.01)$, but not poststress. The ventromedial hypothalamus showed higher CRH-R2 binding under both conditions $(p<0.05)$. The central, but not basolateral, amygdala of HABs showed a tendency towards higher CRH-R2 binding under basal conditions $(p=0.08)$, which reached significance $(p<0.05)$ after stressor exposure. Further, the dorsal raphe revealed a tendency towards higher $\mathrm{CRH}-\mathrm{R} 2$ binding in $\mathrm{HAB}$ rats after stress $(p=0.06)$.

\section{AVP and OXT}

Basal and poststress mRNA expression of AVP (Figures $3-5)$. Within the PVN, significant line-specific differences were detectable (two-way ANOVA, line $\mathrm{F}_{1,19}=6.28, p=0.02$; treatment $\mathrm{F}_{1,19}=0.022, p=0.88 ;$ interaction $\mathrm{F}_{1,19}=1.23$, $p=0.28$ ) with HABs showing higher AVP expression than LABs (Figures $3 \mathrm{~b}$ and $4 \mathrm{a}$ ). Over-expression of AVP in the PVN of HABs occurred predominantly under basal conditions without showing a further elevation $2 \mathrm{~h}$ after open-arm exposure. Analysis of the PVN subdivisions (Swanson and Sawchenko, 1983), particularly under basal conditions, revealed a higher AVP expression in the predominantly magnocellular region of the PVN of HABs (two-way ANOVA, line $\mathrm{F}_{1,19}=5.39, p=0.04$; treatment $\mathrm{F}_{1,19}=3.43, p=0.09$; interaction $\mathrm{F}_{1,19}=2.87, p=0.12$; Figure 5a). Since expression in the predominantly parvocellular part was below the detection limit of the gray-scale method, we analyzed basal AVP mRNA labeling in the parvocellular somata by counting the number of silver grains per cell in dipped slides. This revealed an enhanced AVP expression in HAB rats (two-way ANOVA, line $\mathrm{F}_{1,19}=5.61, p=0.03$; treatment $\mathrm{F}_{1,19}=14.6$, $p=0.001$; interaction $\mathrm{F}_{1,19}=6.49, p=0.02$; Figure $5 \mathrm{~b}$ ). Silver grains in magnocellular neurons were found to be too densely packed to allow counting. After stressor exposure, no linespecific differences were found in either PVN subdivision.

In contrast to the PVN, the mRNA expression of AVP within the SON of male $\mathrm{HAB}$ and $\mathrm{LAB}$ rats did not differ under both basal and poststress conditions (two-way ANOVA, line $\mathrm{F}_{1,19}=0.053, p=0.82$; treatment $\mathrm{F}_{1,19}=0.15$, $p=0.70$; interaction $\mathrm{F}_{1,19}=0.86, p=0.36$; Figure $4 \mathrm{~b}$ ).

Basal and poststress mRNA expression of OXT. In contrast to AVP, the expression patterns of OXT mRNA within the PVN of HAB and $L A B$ rats failed to reveal line-specific differences (two-way ANOVA, line $\mathrm{F}_{1,19}=0.068, p=0.80$; treatment $\mathrm{F}_{1,19}=15.7, p=0.0008$; interaction $\mathrm{F}_{1,19}=2.96$, $p=0.10$ ) both under basal conditions (HAB: $89.6 \pm 4.4 \mathrm{nCi} /$ $\mathrm{mg}, \mathrm{LAB}: 73.3 \pm 14.1 \mathrm{nCi} / \mathrm{mg}$ ) and $2 \mathrm{~h}$ after exposure to an open arm of the EPM (HAB: $108 \pm 7.7 \mathrm{nCi} / \mathrm{mg}$, LAB: $120 \pm 3.4 \mathrm{nCi} / \mathrm{mg})$.

Basal and poststress. AVP V1a-R binding (Table 4). Binding of the selective ligand to the AVP V1a-R subtype was detectable in most of the brain areas studied. However, 
Table 2 Binding at CRH-RI (dpm/mg) Within Brain Areas of Male HAB and LAB Rats Under Basal Conditions and 30 min Poststress (I0-min Open-Arm Exposure)

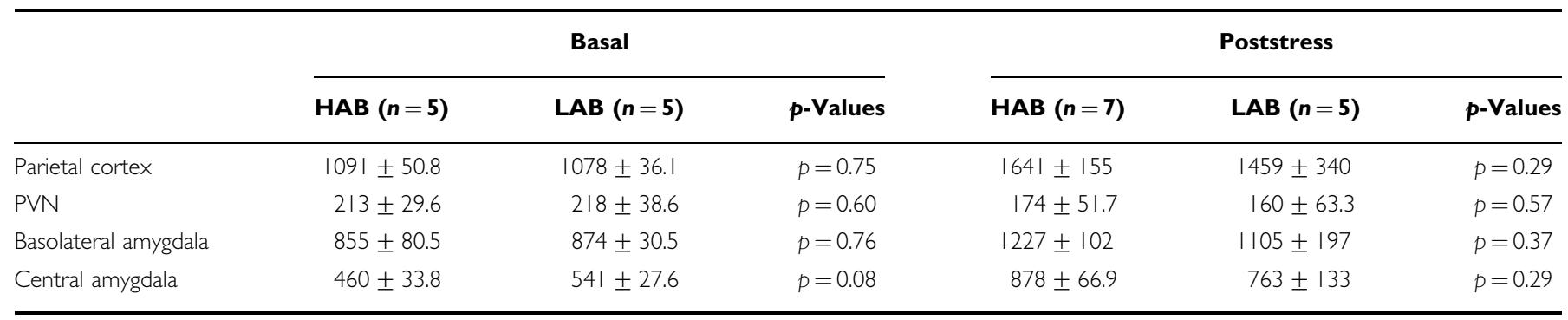

Data are means \pm SEM.

Table 3 Binding at CRH-R2 (dpm/mg) Within Brain Areas of Male HAB and LAB Rats Under Basal Conditions and 30 min Poststress (I0-min Open-Arm Exposure)

\begin{tabular}{|c|c|c|c|c|c|c|}
\hline & \multicolumn{3}{|c|}{ Basal } & \multicolumn{3}{|c|}{ Poststress } \\
\hline & HAB $(n=5)$ & LAB $(n=5)$ & $p$-Values & HAB $(n=7)$ & LAB $(n=5)$ & $p$-Values \\
\hline PVN & $553 \pm 42.9$ & $346 \pm 42.9$ & $p=0.009$ & $358 \pm 32.0$ & $311 \pm 34.0$ & $p=0.46$ \\
\hline Ventromedial hypothalamus & $732 \pm 45.2$ & $577 \pm 41.6$ & $p=0.016$ & $1068 \pm 74.5$ & $645 \pm 186$ & $p=0.042$ \\
\hline Dorsal raphe & $669 \pm 10.7$ & $623 \pm 65.8$ & $p=0.47$ & $504 \pm 105$ & $293 \pm 46.4$ & $p=0.062$ \\
\hline
\end{tabular}

Data are means \pm SEM.
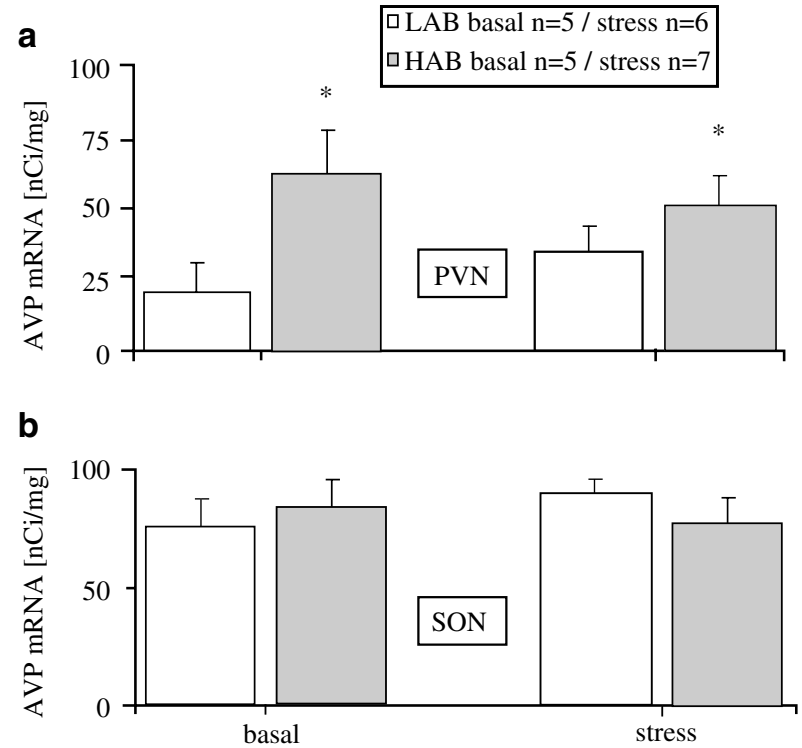

Figure 4 mRNA expression of AVP $(\mathrm{nCi} / \mathrm{mg})$ in the (a) PVN and (b) $S O N$ of male $H A B$ and $L A B$ rats under basal conditions and $2 \mathrm{~h}$ poststress ( I0-min exposure to an open arm of the EPM). Data are means + SEM. $* p<0.05$ vs LAB.

V1a-R binding was not significantly different between the lines under either basal conditions or $2 \mathrm{~h}$ after a 10 -min open-arm exposure. In both the PVN and SON, binding was very low or not detectable.

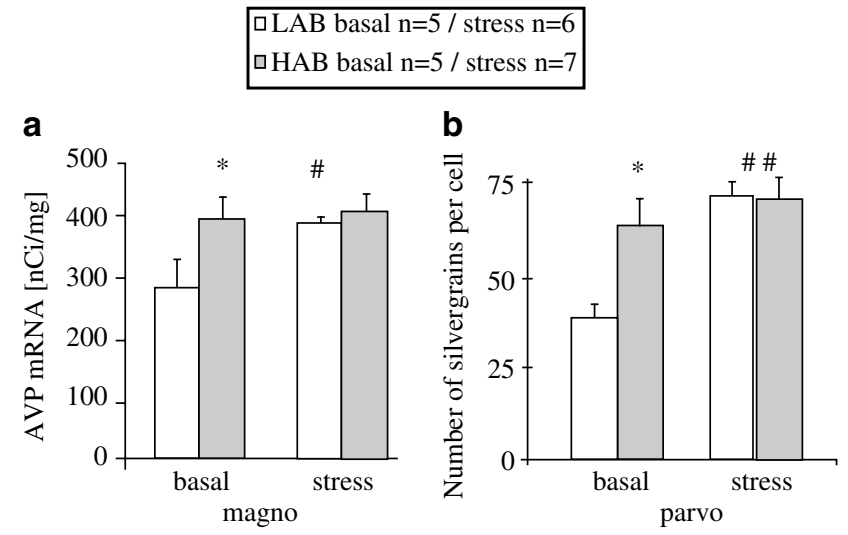

Figure 5 mRNA expression of AVP in either (a) magnocellular (estimated via nuclear films) or (b) parvocellular (number of silver grains within somata indicating labeled mRNA) PVN neurons of male HAB and $L A B$ rats under basal conditions or $2 \mathrm{~h}$ poststress ( $10-$ min exposure to an open arm of the EPM). Data are means \pm SEM. ${ }^{\#} p<0.05,{ }^{\# \#} p<0.01$ vs basal, * $p<0.05$ vs LAB.

Basal and stress-induced release of AVP and OXT within the PVN (Figure 6). Basal and stimulated AVP and OXT release within the PVN of $\mathrm{HAB}$ and $\mathrm{LAB}$ rats were estimated by microdialysis.

Exposure to an open arm of the plus-maze failed to alter both AVP and OXT release in either line. In contrast, in both lines $10 \mathrm{~min}$ of forced swimming induced a significant increase in either AVP (two-way ANOVA over dialysates 
Table 4 Binding of the Selective AVP VIa-R Ligand ${ }^{125}$-lin-AVP (nCi/mg) in Selected Brain Areas of Male HAB and LAB Rats Under Basal Conditions and $2 \mathrm{~h}$ Poststress (I0-min Open-Arm Exposure)

\begin{tabular}{|c|c|c|c|c|c|c|}
\hline & \multicolumn{3}{|c|}{ Basal } & \multicolumn{3}{|c|}{ Poststress } \\
\hline & HAB $(n=5)$ & LAB $(n=5)$ & $p$-Values & HAB $(n=5)$ & LAB $(n=4)$ & $p$-Values \\
\hline Medial septum & $120 \pm 43.6$ & $82.2 \pm 24.3$ & $p=0.08$ & $48.2 \pm 6.86$ & $49.1 \pm 3.82$ & $p=0.46$ \\
\hline BSTLD & $123 \pm 19.8$ & $120 \pm 17.3$ & $p=0.60$ & $126 \pm 7.40$ & $112 \pm 8.69$ & $p=0.14$ \\
\hline SON & \multicolumn{2}{|c|}{ Not detectable } & \multicolumn{4}{|c|}{ Not detectable } \\
\hline SCN & $27.3 \pm 2.09$ & $25.7 \pm 1.73$ & $p=0.35$ & $25.4 \pm 0.55$ & $24.4 \pm 0.80$ & $p=0.33$ \\
\hline AVVL & $29.0 \pm 1.29$ & $28.5 \pm 1.45$ & $p=0.68$ & $30.1 \pm 1.09$ & $27.2 \pm 1.37$ & $p=0.05$ \\
\hline $\mathrm{VL}$ & $74.4 \pm 10.8$ & $88.7 \pm 4.97$ & $p=0.25$ & $84.9 \pm 6.10$ & $85.5 \pm 11.0$ & $p=0.71$ \\
\hline Parathenial nucleus & $101 \pm 9.86$ & $93.5 \pm 9.34$ & $p=0.33$ & $115 \pm 3.51$ & $126 \pm 10.8$ & $p=0.18$ \\
\hline Thalamic cortex left & $22.3 \pm 1.49$ & $21.1 \pm 1.08$ & $p=0.53$ & $25.1 \pm 2.17$ & $24.4 \pm 2.18$ & $p=0.54$ \\
\hline Hippocampal cortex right & $23.7 \pm 1.00$ & $25.4 \pm 1.28$ & $p=0.35$ & $25.0 \pm 1.43$ & $27.1 \pm 1.71$ & $p=0.14$ \\
\hline Hippocampal cortex left & $19.6 \pm 0.42$ & $20.0 \pm 0.45$ & $p=0.40$ & $22.8 \pm 1.05$ & $23.8 \pm 2.28$ & $p=0.71$ \\
\hline Hippocampus & $24.6 \pm 1.65$ & $23.2 \pm 1.15$ & $p=0.40$ & $24.5 \pm 0.64$ & $23.9 \pm 0.70$ & $p=0.33$ \\
\hline VPM & $94.8 \pm 9.97$ & $84.0 \pm 7.75$ & $p=0.25$ & $103 \pm 5.69$ & $103 \pm 9.48$ & $p=0.46$ \\
\hline$C M$ & $101 \pm 9.86$ & $93.5 \pm 9.34$ & $p=0.33$ & $113 \pm 3.60$ & $123 \pm 10.9$ & $p=0.27$ \\
\hline AHP & $81.1 \pm 8.26$ & $70.6 \pm 5.34$ & $p=0.30$ & $88.4 \pm 6.54$ & $66.4 \pm 5.22$ & $p=0.028$ \\
\hline
\end{tabular}

Data are means \pm SEM.

Abbreviations according to Paxinos and Watson (1998): AHP: anterior hypothalamic area, posterior part; AVVL: anteroventral thalamic nucleus, ventrolateral part; BSTL LD/LI: bed nucleus of the stria terminalis, lateral division, dorsal part/intermediate part; CM: central medial thalamic nucleus; PVN: paraventricular nucleus; SCN: suprachiasmatic nucleus; SON: supraoptic nucleus; VL: ventrolateral thalamic nucleus; VPM: ventral posteromedial thalamic nucleus; VPPC: ventral posterior thalamic nucleus, parvicellular part.

$1-7$, factor time: $\mathrm{F}_{6,72}=5.80, p<0.0001$, rat line: $\mathrm{F}_{1,12}=2.33$, $p=0.15$ ) or OXT (two-way ANOVA over dialysates 1-7, factor time: $\mathrm{F}_{7,98}=11.0, p<0.0001$, rat line: $\mathrm{F}_{1,14}=$ $0.15, p=0.71$, interaction: $\mathrm{F}_{7,98}=0.40, p=0.90$ ) release. While OXT release within the PVN failed to show any significant line difference, AVP release was higher in the PVN of HAB rats under basal and stimulated conditions. In more detail, the comparison between the first dialysates only revealed an elevated basal release of AVP in HABs $(p=0.028)$. Similarly, the rise in AVP from the fifth (undisturbed) to the sixth (forced swimming) dialysate was significantly higher in HABs (ratio: $\mathrm{HAB} 0.29 \pm 0.08$, LAB $0.064 \pm 0.04, p=0.02$ ).

After the experiment, the release pattern of AVP upon microdialysis with a hypertonic medium revealed a tendency towards a higher rise in AVP from the first to the third dialysate in HABs (ratio: HAB $33.3 \pm 9.2$, LAB $14.2 \pm 5.9, p=0.057)$, potentially indicating a higher releasable pool of AVP in the PVN of HAB animals. Again, OXT failed to reveal divergent release patterns between $\mathrm{HAB}$ and $\mathrm{LAB}$ animals after microdialysis with a hypertonic medium (ratio: HAB $21.5 \pm 5.1$, LAB $25.5 \pm 6.7, p=0.75$ ), indicating no difference in the releasable pool of PVN OXT between the lines.

The results representing hyper-release of AVP, but not OXT, under basal and posthypertone conditions in HAB rats were replicated in a follow-up study measuring AVP (significant line difference, $\mathrm{HAB}>\mathrm{LAB}$, basal $p=0.011$, posthypertonic $p=0.013$ ) and OXT (no line difference, basal $p=0.67$, posthypertonic $p=0.39$ ) in the same microdialysates (same animals, same timepoints, Figure 6 right) reinforcing the previous result of an enhanced intra-PVN release of AVP accompanying the enhanced AVP mRNA expression.

Administration of an AVP V1-R antagonist via inverse microdialysis (Figure 7). Administration of the V1-R antagonist via inverse microdialysis into the PVN (histological example see Figure 2) tended to reduce the anxietyrelated behavior of HAB males on the EPM. Both percent entries into $(p=0.05)$ and percent time spent on $(p=0.05)$ the open arms of the maze tended towards being elevated by antagonist treatment. The total number of closed-arm entries, indicative of locomotor activity, remained unchanged after antagonist treatment $(p=0.49)$. Intra-PVN administration of the V1-R antagonist shifted the behavior of HAB males in the forced swim test toward a more active coping style as shown by reduced floating $(p<0.05)$. In contrast, latency to floating (control $55.6 \pm 13.5 \mathrm{~s}$, antagonist $88.9 \pm 28.6 \mathrm{~s}, p=0.60$ ), duration of swimming (control $509 \pm 7.3 \mathrm{~s}$, antagonist $515 \pm 12.5 \mathrm{~s}, p=0.34$ ), and struggling $(p=0.37)$ were not changed by the V1-R antagonist treatment. 

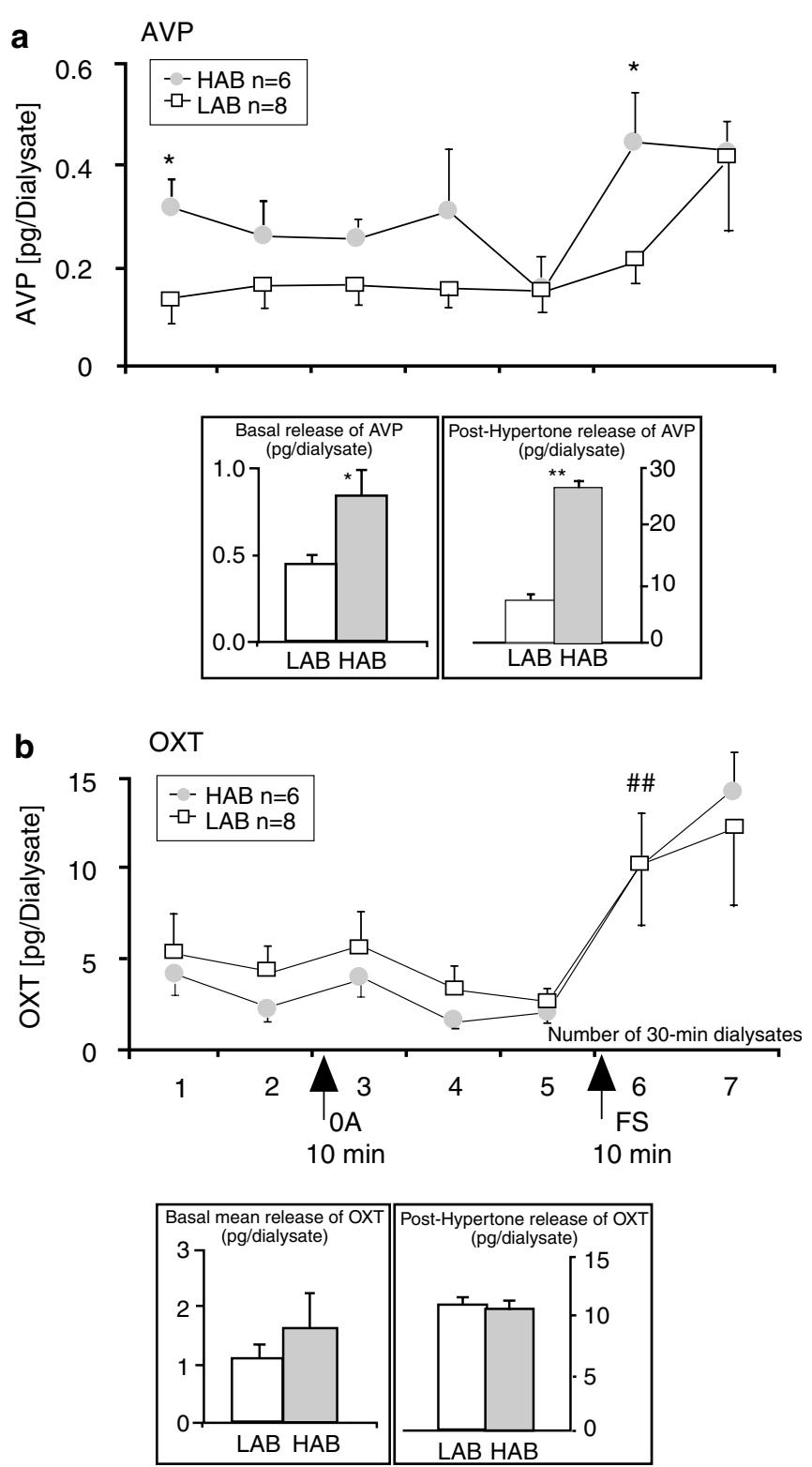

Figure 6 Concentrations of (a) AVP and (b) OXT in 30-min microdialysates of the right PVN of male $H A B$ and $L A B$ rats under basal conditions (dialysates I and 2) and after mild emotional (I0-min exposure to an open arm of the EPM, OA, at the beginning of the third dialysate) and physical (10-min forced swimming, FS, $19^{\circ} \mathrm{C}$ at the beginning of the sixth dialysate) stress. Dialysates no. 4, 5, and 7 were sampled under undisturbed conditions. The panels below demonstrate the results of a follow-up experiment measuring AVP and OXT in the same dialysates reproducing the results of the first study. Data are means $\pm S E M . \# p<0.01$ vs fifth dialysate; ${ }^{*} p<0.05$ vs LAB.

\section{DISCUSSION}

In this series of experiments, we demonstrated altered neuropeptide expression, intracerebral release, and binding patterns, which are likely to underlie hyper-emotionality and HPA axis hyper-reactivity in rats bred for high trait anxiety (HABs). In these animals, reduced CRH mRNA expression was shown within the BNST. While the binding to CRH-R1 failed to show significant differences between the lines, CRH-R2 binding was significantly elevated in the
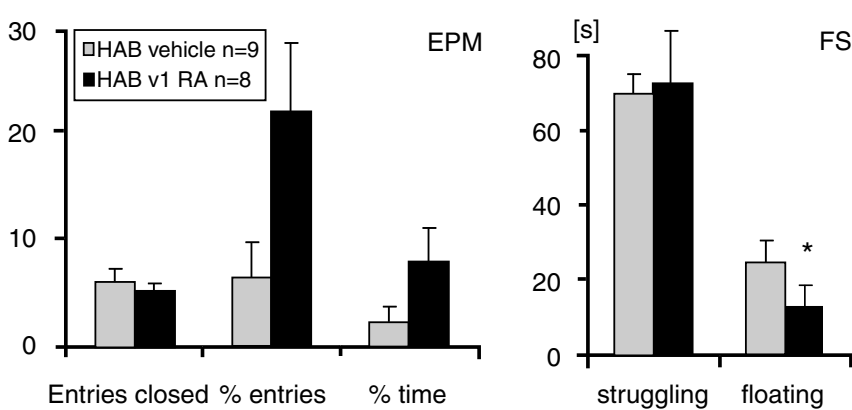

Figure 7 Anxiety-related (\% entries into and \% time spent on the open arms) and locomotor (closed-arm entries) behavior of HAB males on the EPM after retrodialysis administration of either vehicle (sterile Ringer's) or VI antagonist (delivery of $5 \mathrm{ng}$ ) into both PVNs within $30 \mathrm{~min}$ prior to testing. After $30 \mathrm{~min}$, coping strategy after both treatments was measured in a forced swim test $\left(\mathrm{FS} ; 19^{\circ} \mathrm{C}, 10 \mathrm{~min}\right)$. Data are means $\pm \mathrm{SEM}$. ${ }^{*} p<0.05$ vs vehicle.

PVN, ventromedial hypothalamus, and central amygdala of HABs. In both basal and poststress conditions, AVP mRNA expression was selectively elevated within the PVN of HAB compared to $\mathrm{LAB}$ rats. Further, $\mathrm{HAB}$ rats showed an elevated release of AVP within the PVN under basal conditions, after forced swimming, and a tendency towards elevated release after hypertonic stimulation. In contrast, the measurement of OXT expression and release in the same animals failed to reveal any line differences. While binding to the AVP V1a-R subtype was not line-divergent in any brain area studied, infusion of a V1-R antagonist directly into the PVN of HABs resulted in a trend towards reduced anxiety and a significantly enhanced active stress coping indicative of antidepressive effects. Thus, particularly AVP over-expression and over-release within the PVN seem to be critically involved in both behavioral and neuroendocrine phenomena linked to trait anxiety/depression.

\section{Corticotropin-Releasing Hormone}

Impact on HPA axis (re)activity. CRH expressed within the PVN and transported to the anterior pituitary stimulates the HPA axis as an ACTH secretagogue (Rivier and Vale, 1983; Plotsky, 1991). Accordingly, in conditions of HPA hyperreactivity, for example in depressed patients (Raadsheer et al, 1994) or in rats after chronic stress (Aguilera, 1994; Herman et al, 1995; Ma et al, 1999), an enhanced expression of CRH was shown within the PVN. Here, both CRH mRNA expression and CRH-R1 binding (Tables 1 and 2) failed to show significant line-specific differences, thus making the critical involvement of CRH expression and CRH-R1 binding in HPA axis hyper-reactivity of HABs rather unlikely. A difference in pituitary CRH-R1 between the lines, contributing to HPA axis hyper-reactivity can largely be excluded since ACTH secretion into the blood of HABs and LABs failed to show differential sensitivity to i.v. CRH (Liebsch et al, 1998b), suggesting that this receptor subtype does not play a critical role in neuroendocrine aberrations associated with trait anxiety.

In contrast to CRH-R1, CRH-R2 binding was elevated in the PVN of HABs (Table 3) and might mediate a stimulatory effect of intra-PVN released CRH on HPA axis function (Jezova et al, 1999). Since there are CRH projections from 
the BNST to the PVN, which could regulate CRH synthesis in the PVN (Champagne et al, 1998), the decreased CRH mRNA expression within the BNST of HABs would have additional effects on the $\mathrm{PVN}$, which remain to be shown.

Impact on anxiety-related behavior and stress coping. Administered into the central amygdala before exposure to the EPM, CRH reduced exploration independent of HPA axis activation (Merlo Pich et al, 1993). However, in the same area (Tazi et al, 1987) and within the BNST (Nijsen et al, 2001), CRH administration seems to facilitate locomotion in a familiar environment. Thus, the relatively high $\mathrm{CRH}$ expression both in the central amygdala $(p=0.08)$ and the BNST $(p<0.05$, Table 1$)$ of LABs under basal conditions might lead to enhanced local release and may thus be related to their predominantly active living style detected by home cage observations (Liebsch et al, 1998b; Henniger et al, 2000). Further, regarding the presence of $\mathrm{CRH}$ pathways from the central amygdala to the BNST (for a review, see Steckler and Holsboer, 1999), the increased $\mathrm{CRH}$ mRNA expression in the central amygdala of LABs may also precede an increased $\mathrm{CRH}$ release in the BNST.

While the differential release of serotonin in the PVN and dorsal hippocampus of HABs and LABs points towards a contribution of serotonergic neurotransmission to divergent HPA axis reactivity and emotionality (Umriukhin et al, 2003), no significant line-specific differences in $\mathrm{CRH}$ expression were found in the raphe nucleus, the origin of the serotonergic system (Price et al, 1998).

The effects of $\mathrm{CRH}$ on emotional behavior have been reported to be predominantly mediated by the CRH-R1 subtype (Liebsch et al, 1995, 1999; Heinrichs et al, 1997, 2002; Kehne et al, 2000). In our study, none of the examined areas revealed line differences in CRH-R1 binding (Table 2), which provides evidence that the CRH-R1 is not causally involved in trait anxiety. However, since administration of the selective CRH-R1 antagonist R121919 had pronounced anxiolytic/antidepressive effects in HABs only (Keck et al, 2001), differential postreceptor mechanisms through which the CRH-R1 subtype could contribute to this hyper-anxiety cannot be excluded. Recent reports also describe participation of the CRH-R2 in mediating anxiogenic effects (Radulovic et al, 1999, 2000). This interpretation is further supported by the observed reduction of anxiety in the EPM after i.c.v. administration of the CRH-R2 selective antagonist ASV-30 (Takahashi et al, 2001), although predominantly anxiolytic properties of this receptor subtype were described so far (Bale et al, 2000; Kishimoto et al, 2000). Further, the CRH-R2 is postulated to play a role in stress coping (Liebsch et al, 1999). As our rat lines differ in this behavioral parameter, the higher binding of CRH-R2 within the PVN, the amygdala, and the ventromedial hypothalamus of HABs (Table 2) should attract further attention to the behavioral significance of this receptor subtype.

\section{Arginine-8-Vasopressin}

Impact on HPA axis (re)activity. At the anterior pituitary level, AVP originating predominantly from parvocellular
PVN neurons and released into the portal blood reinforces the stimulation of ACTH release by CRH (Plotsky, 1991). The upregulation of AVP mRNA expression, particularly under basal conditions, within parvocellular somata of the PVN of HABs (Figure 5) may precede the elevated AVP secretion into the pituitary portal blood that is likely to promote HPA axis hyper-reactivity to stressors. Accordingly, the pathological outcome of the combined dexamethasone suppression/CRH challenge test found in HABs could be brought back to normal by i.v. administration of a selective AVP V1-R antagonist (Keck et al, 2002). Although not confirmed by the amount of silver grains in single cells, our images show a distinct upregulation of basal AVP mRNA expression also in the magnocellular subdivision of the PVN of HABs (Figure 5a), indicating a causal involvement of both parvo- and magnocellular PVN AVP neurons in the $\mathrm{HAB}$ phenotype. Supporting this notion, antidepressive paroxetine treatment normalized the hyperexpression of AVP within the entire PVN, accompanying its behavioral and neuroendocrine actions (Keck et al, 2003). In contrast to its stimulatory action on $\mathrm{ACTH}$ release at the pituitary level, AVP released within the PVN was described to provide a negative tonus on HPA axis activity (Makara et al, 1996; Wotjak et al, 1996). Accordingly, the elevated AVP release found in the PVN of HABs under basal conditions (Figure 6a) may exert a tonic inhibition on the HPA axis, which might otherwise be chronically elevated due to exaggerated AVP secretion at the level of the median eminence. However, since the PVN is an extremely heterogeneous nucleus containing several types of neurosecretory neurons, it remains to be shown whether the amount of AVP microdialyzed here truly reflects the portion of the neuropeptide released to become involved in differential HPA axis regulation.

Open-arm exposure has been shown to increase the activity of the HPA axis, with a stronger effect in HABs than in LABs (Landgraf et al, 1999), but this stimulus failed to increase intra-PVN release of AVP in both lines. In HABs, this lack in stimulation might be explained by the enhanced basal intra-PVN release of AVP prior to stressor exposure. As suggested by Weiss et al (1992), the response to a challenge is reduced proportionally if a system is operating at a higher basal tone, making the system relatively insensitive to stressor exposure. Our in situ hybridization data favor this hypothesis, since only LABs responded to stress with an increase in AVP mRNA expression in the PVN (Figures 4a and 5), whereas HABs already showed enhanced basal expression that was not further elevated by the weak stressor of open-arm exposure. However, even LABs failed to increase significantly intra-PVN release of AVP after open-arm exposure, suggesting that the stimulus intensity of open-arm exposure is generally too weak to stimulate intra-PVN release of AVP. Given that AVP may provide a negative tonus to HPA axis reactivity, the lack of an AVP increase during open-arm exposure might permit the HPA axis of HABs to respond to this stimulus with an enhanced ACTH secretion (Landgraf et al, 1999). According to this hypothesis, the increase of AVP in HABs during forced swimming (Figure 6a) might exert a more effective inhibition of the HPA axis response, adjusting it to a similar level as in LABs. Indeed, similar ACTH and corticosterone responses to forced swimming in both lines were shown by 
Liebsch et al (1998a) and Neumann et al (1998). Concerning V1a-R binding within the PVN, no line differences could be shown either under basal or stimulated conditions (Table 4), suggesting that line-specific divergences in neuroendocrine and behavioral parameters are due to differential intracerebral release patterns rather than to differences in V1a-R binding in the PVN or other brain areas.

Impact on anxiety-related behavior and stress coping. Released centrally and interacting with V1a-R (Raggenbass et al, 1998) and V1b-R (Griebel et al, 2002), AVP is well known to be involved in multiple behavioral processes including cognition and emotionality (De Wied et al, 1988; Landgraf, 1995; Landgraf et al, 1995a; Engelmann et al, 1996; Liebsch et al, 1996; Makara et al, 1996; Young, 2002). In all the brain areas studied here, V1a-R binding failed to differentiate between the lines, suggesting that a critical involvement of this receptor subtype in trait anxiety/ depression is rather unlikely. Only in the septum, where $\mathrm{AVP}$ and its V1a-R were reported to promote learning and memory capacities, and stress coping strategies (Landgraf et al, 1995a; Engelmann et al, 1996; Ebner et al, 1999), the $\mathrm{HAB}$ rats showed enhanced receptor binding (Keck et al, 2003). Albeit in the present study this result was reproduced in tendency only (Table 4), this finding is in line with our recent data indicating an improved short-term memory in $\mathrm{HABs}$ in the social discrimination test (Landgraf and Wigger, 2002). The same was true for rats with an overexpression of the vole Vla receptor in their septum by viral vector-mediated transgene transfer (Landgraf and Wigger, 2003). Since the septum was also reported to be involved in the expression of anxiety-related behavioral features (Landgraf et al, 1995a), future studies will appoint the contribution of AVP released and bound within this region to hyperanxiety/depression in $\mathrm{HAB}$ rats.

In the present study, we used inverse microdialysis for bilateral administration of a V1-R antagonist directly into the PVN. This approach was established to avoid an acute (and more stressful) injection and to deliver an efficacious amount of the antagonist continuously (Engelmann et al, 1992), thus blocking the effect of intra-PVN released AVP in this way. Compared to controls, the anxiety-related behavior of antagonist-treated $\mathrm{HAB}$ rats tended to be reduced (Figure 7a), indicating an anxiogenic effect of AVP released within the PVN. Further, depression-like behavior was significantly reduced upon treatment (Figure $7 \mathrm{~b}$ ), suggesting that AVP, in addition to its neuroendocrine effects, is likely to trigger behavioral consequences in this hypothalamic area. Convincingly, long-term treatment of $\mathrm{HAB}$ rats with the antidepressant drug paroxetine (Keck et al, 2002) resulting in both normalization of the dexamethasone/CRH test and reduction of depression-like behavior in the forced swim test was accompanied by normalization of AVP over-expression in the PVN, thus providing further evidence supporting the critical involvement of AVP in indices of neuroendocrine and behavioral pathology in HABs. Noteworthy, recent results in $\mathrm{HAB}-\mathrm{M} / \mathrm{LAB}-\mathrm{M}$ mice bred in our laboratory (Krömer et al, unpublished) also showed a remarkable overexpression of AVP in the PVN of anxious/depressive mice (Wigger et al, unpublished) similar to the data gained in anxious/depressive $\mathrm{HAB}$ rats as reported here.

\section{Oxytocin}

Centrally released OXT has recently been reported to contribute to basal and stress-induced regulation of the HPA axis (Gibbs, 1986; Neumann et al, 2000a, b) as well as of anxiety-related behavior (Neumann et al, 2000b; Bale et al, 2001) and was, therefore, included here as one of the neuropeptides potentially involved in neuroendocrine and behavioral differences between HAB and LAB rats. Similar to AVP, intra-PVN OXT release was not triggered by openarm exposure, whereas it was similarly stimulated in both lines by forced swimming (Figure 6b). In contrast to the AVP system, both mRNA expression and intranuclear release of OXT within the PVN were similar in both lines under either condition, making an involvement of intraPVN OXT in line-divergent HPA axis regulation rather unlikely.

\section{Perspective}

The data obtained in this study reveal an enhanced activity of the AVP system in the hypothalamic PVN of male HAB animals, suggesting that AVP rather than CRH or OXT plays a critical role in behavioral and neuroendocrine phenomena linked to trait anxiety/depression. More specifically, AVP mRNA over-expression in the parvocellular PVN of HAB rats precedes (i) elevated intra-PVN release of AVP resulting in enhanced anxiety/depression-related behavior and (ii) elevated AVP secretion into the pituitary portal blood resulting in HPA axis hyper-reactivity among other roles. The behavioral and neuroendocrine phenotyping of $\mathrm{HAB}$ and LAB animals thus provides compelling evidence for a critical and multiple involvement of AVP in anxietyrelated behavior. Based on differential phenotyping, future work will focus primarily on the AVP gene as a candidate gene underlying trait anxiety/depression. Preliminary approaches have revealed single nucleotide polymorphisms (SNPs) in the promoter region of the AVP gene of HAB, but not $\mathrm{LAB}$, rats, whereas the $\mathrm{CRH}$ gene failed to reveal any differences (Murgatroyd et al, unpublished). Nevertheless, there are also differences in the CRH system between $\mathrm{HAB}$ and $\mathrm{LAB}$ rats, particularly with respect to CRH mRNA expression in the central amygdala and the BNST, as well as differences in CRH-R2 density, which altogether could contribute to the different emotionality of the two animal lines. Thus, studying hypothalamic neuropeptide systems and their involvement in trait anxiety in more detail might provide deeper insights into the neurobiological mechanisms underlying anxiety disorders and depression as a prerequisite for the development of improved therapeutic strategies.

\section{ACKNOWLEDGEMENTS}

We greatly appreciate the professional technical assistance of Patrick Lörscher, Katrin Moschke, Marina Zimbelmann, Gabriele Kohl, and Andrea Zahn. Further, we thank Dr Marianne Müller, Lorraine Smith, and Matthew Aldag for the methodological assistance in performing the in situ hybridization as well as the receptor autoradiography. We disclose any involvement, financial, or otherwise that might potentially bias their work. These studies were supported by 
the Deutsche Forschungsgemeinschaft (AW, RL) and NIH Grants MH50113 (PMP) and MH58922.

\section{REFERENCES}

Aguilera G (1994). Regulation of pituitary ACTH secretion during chronic stress. Front Neuroendocrinol 15: 321-350.

Bale TL, Contarino A, Smith GW, Chan R, Gold LH, Sawchenko PE et al (2000). Mice deficient for corticotropin-releasing hormone receptor-2 display anxiety-like behaviour and are hypersensitive to stress. Nat Genet 24: 410-414.

Bale TL, Davis AM, Auger AP, Dorsa DM, McCarthy MM (2001). CNS region-specific oxytocin receptor expression: importance in regulation of anxiety and sex behavior. J Neurosci 21: 2546-2552.

Champagne D, Beaulieu J, Drolet G (1998). CRFergic innervation of the paraventricular nucleus of the rat hypothalamus: a tracttracing study. J Neuroendocrinol 10: 19-131.

De Kloet ER, Joels M, Oitzl M, Sutanto W (1991). Implication of brain corticosteroid receptor diversity for the adaptation syndrome concept. Meth Arch Exp Pathol 14: 104-132.

De Kloet ER, Oitzl MS, Joels M (1999). Stress and cognition: are corticosteroids good or bad guys? TINS 22: 422-426.

De Wied D, Joels M, Burbach JPH, de Jong W, de Kloet ER, Gaffori OWJ et al (1988). Vasopressin effects on the central nervous system. In: Negro-Villar A, Conn PM (eds). Peptide Hormones: Effects and Mechanisms of Action Vol. 1 CRC Press: Boca Raton, FL. pp 97-140.

Driscoll P, Escorihuela RM, Fernandez-Teruel A, Giorgi O, Schwegler H, Steimer T et al (1998). Genetic selection and differential stress responses. The Roman lines/strains of rats. Ann NY Acad Sci 851: 501-510.

Ebner K, Wotjak CT, Holsboer F, Landgraf R, Engelmann M (1999). Vasopressin released within the septal brain area during swim stress modulates the behavioral stress response in rats. Eur J Neurosci 11: 997-1002.

Engelmann M, Ebner K, Landgraf R, Holsboer F, Wotjak C (1999). Emotional stress triggers intrahypothalamic but not peripheral release of oxytocin in male rats. J Neuroendocrinol 11: 867-872.

Engelmann M, Ludwig M, Landgraf R (1992). Microdialysis administration of vasopressin and vasopressin antagonists into the septum during pole-jumping behavior in rats. Behav Neural Biol 58: 51-57.

Engelmann M, Ludwig M, Landgraf R (1994). Simultaneous monitoring of intracerebral release and behavior: vasopressin improves social recognition. J Neuroendocrinol 6: 391-395.

Engelmann M, Wotjak CT, Ludwig M, Neumann ID, Landgraf R (1996). Behavioral consequences of intracerebral vasopressin and oxytocin: focus on learning and memory. Neurosci Biobehav Rev 20: 341-358.

Escorihuela RM, Fernandez-Teruel A, Gil L, Aguilar R, Tobena A, Driscoll P (1999). Inbred Roman high- and low-avoidance rats: differences in anxiety, novelty-seeking, and shuttlebox behaviors. Physiol Behav 67: 19-26.

Gibbs DM (1986). Vasopressin and oxytocin: hypothalamic modulators of the stress response: a review. Psychoneuroendocrinology 11: 131-139.

Griebel G, Simiand J, Gal CSL, Wagnon J, Pascal M, Scatton B et al (2002). Anxiolytic- and antidepressant-like effects of the non-peptide vasopressin $\mathrm{V}-1 \mathrm{~b}$ receptor antagonist, SSR149415, suggest an innovative approach for the treatment of stress-related disorders. Proc Natl Acad Sci USA 99: 6370-6375.

Grigoriadis DE, Liu XJ, Vaughn J, Palmer SF, True CD, Vale WW et al (1996). 125I-Tyro-sauvagine: a novel high affinity radioligand for the pharmacological and biochemical study of human corticotropin-releasing factor 2 alpha receptors. Mol Pharmacol 50: 679-686.
Heinrichs SC, Lapsansky J, Lovenberg TW, De Souza EB, Chalmers DT (1997). Corticotropin-releasing factor CRF1, but not CRF2, receptors mediate anxiogenic-like behavior. Regul Peptides 71: $15-21$.

Heinrichs SC, De Souza EB, Schultheis G, Lapsansky J, Grigoriadis DE (2002). Brain penetrance, receptor occupancy and antistress in vivo efficacy of a small molecule corticotropin-releasing factor type 1 receptor selective antagonist. Neuropsychopharmacology 27: 194-202.

Henniger MSH, Ohl F, Hölter SM, Weißenbacher P, Toschi N, Lörscher $\mathrm{P}$ et al (2000). Unconditioned anxiety and social behaviour in two rat lines selectively bred for high and low anxiety-related behaviour. Behav Brain Res 111: 153-163.

Herman JP, Adams D, Prewitt C (1995). Regulatory changes in neuroendocrine stress-integrative circuitry produced by a variable stress paradigm. Neuroendocrinology 61: 180-190.

Holsboer F (1989). Psychiatric implications of altered limbichypothalamic-pituitary-adrenocortical activity. Eur Arch Psychiatr Neurol Sci 238: 302-322.

Ivell R, Richter D (1984). Structure and comparison of the oxytocin and vasopressin genes from rat. Proc Natl Acad Sci USA 81: 2006-2010.

Jezova D, Ochedalski T, Glickman M, Kiss A, Aguilera G (1999). Central corticotropin-releasing hormone receptors modulate hypothalamic-pituitary-adrenocortical and sympathoadrenal activity during stress. Neuroscience 94: 797-802.

Keck ME, Welt T, Mueller MB, Uhr M, Ohl F, Wigger A et al (2003). Downregulation of hypothalamic vasopressinergic hyperdrive is involved in clinically relevant behavioural and neuroendocrine antidepressant drug effects. Neuropsychopharmacology 28: 235-243.

Keck ME, Welt T, Wigger A, Renner U, Engelmann M, Holsboer F et al (2001). The anxiolytic effect of the $\mathrm{CRH}(1)$ receptor antagonist R121919 depends on innate emotionality in rats. Eur J Neurosci 13: 373-380.

Keck ME, Wigger A, Welt T, Müller MB, Gesing A, Reul JMHM et al (2002). Vasopressin mediates the response of the combined dexamethasone/CRH test in hyper-anxious rats: implications for pathogenesis of affective disorders. Neuropsychopharmacology 26: 94-105.

Kehne JH, Coverdale S, McCloskey TC, Hoffman DC, Cassella JV (2000). Effects of the CRF(1) receptor antagonist, CP 154,526, in the separation-induced vocalization anxiolytic test in rat pups. Neuropharmacology 39: 1357-1367.

Kishimoto T, Radulovic J, Radulovic M, Lin CR, Schrick C, Hooshmand F et al (2000). Deletion of CRH R2 reveals an anxiolytic role for corticotropin-releasing hormone receptor- 2 . Nat Genet 24: 415-419.

Landgraf R (1995). Intracerebrally released vasopressin and oxytocin: measurement, mechanisms and behavioural consequences. J Neuroendocrinol 7: 243-253.

Landgraf R, Frank E, Aldag JM, Neumann ID, Ren X, Terwilliger EF et al (2003). Viral vector-mediated gene transfer of the vole V1a vasopressin receptor in the rat septum: improved social discrimination and active social behavior. J Neuroendocrinol 18: 403-411.

Landgraf R, Gerstberger R, Montkowski A, Probst JC, Wotjak CT, Holsboer F et al (1995a). snldsn;lsV1 vasopressin receptor antisense oligodeoxynucleotide into septum reduces vasopressin binding, social discrimination abilities, and anxiety-related behavior in rats. J Neurosci 15: 4250-4258.

Landgraf R, Kubota M, Holsboer F, Wotjak CT (1995b). Release of vasopressin and oxytocin within the brain and into blood: microdialysis and antisense targeting. In: Saito T, Kurokawa K, Yoshida S (eds). Neurohypophysis: Recent Progress of Vasopressin and Oxytocin Research. Amsterdam: Elsevier. pp 243-256. 
Landgraf R, Wigger A (2002). High vs low anxiety-related behavior rats: an animal model of extremes in trait anxiety. Behav Genet 32: 301-314.

Landgraf R, Wigger A (2003). Born to be anxious: neuro-endocrine and genetic correlates of trait anxiety in $\mathrm{HAB}$ rats. Stress.

Landgraf R, Wigger A, Holsboer F, Neumann ID (1999). hyperreactive hypothalamo-pituitary-adrenocortical axis in rats bred for high anxiety-related behaviour. J Neuroendocrinol 11: 405407.

Liebsch G, Landgraf R, Gerstberger R, Probst JC, Wotjak CT, Engelmann $M$ et al (1995). Chronic infusion of a CRH1 receptor antisense oligodeoxynucleotide into the central nucleus of the amygdala reduced anxiety-related behavior in socially defeated rats. Regul Pept 59: 229-239.

Liebsch G, Montkowski A, Holsboer F, Landgraf R (1998a). Behavioural profiles of two Wistar rat lines selectively bred for high or low anxiety-related behaviour. Behav Brain Res 94: 301-310.

Liebsch G, Landgraf R, Engelmann M, Lörscher P, Holsboer F (1999). Differential behavioural effects of chronic infusion of CRH 1 and CRH 2 receptor antisense oligonucleotides into the rat brain. J Psychiatr Res 33: 153-163.

Liebsch G, Linthorst ACE, Neumann ID, Reul JMHM, Holsboer F, Landgraf R (1998b). Behavioral, physiological, and neuroendocrine stress responses and differential sensitivity to diazepam in two Wistar rat lines selectively bred for high- and low-anxiety-related behaviour. Neuropsychopharmacology 19: 381-396.

Liebsch G, Wotjak CT, Landgraf R, Engelmann M (1996). Septal vasopressin modulates anxiety-related behaviour in rats. $\mathrm{Neu}$ rosci Lett 217: 101-104.

Ma XM, Lightman SL, Aguilera G (1999). Vasopressin and corticotropin-releasing hormone gene responses to novel stress in rats adapted to repeated restraint. Endocrinology 140: 3623-3632.

Makara GB, Kiss A, Lolait SJ, Aguilera G (1996). Hypothalamicpituitary corticotroph function after shunting of magnocellular vasopressin and oxytocin to the hypophyseal portal circulation. Endocrinology 137: 580-586.

Merlo Pich E, Heinrichs SC, Rivier C, Miczek KA, Fisher DA, Koob GF (1993). Blockade of pituitary adrenal axis activation induced by peripheral immunoneutralization of corticotropin-releasing factor does not affect the behavioral response to social defeat stress in rats. Psychoneuroendocrinology 18: 495-507.

Neumann I, Ludwig M, Engelmann M, Pittman QJ, Landgraf R (1993). Simultaneous microdialysis in blood and brain: oxytocin and vasopressin release in response to central and peripheral osmotic stimulation and suckling in the rat. Neuroendocrinology 58: 637-645.

Neumann ID, Wigger A, Liebsch G, Holsboer F, Landgraf R (1998). Increased basal activity of the hypothalamo-pituitary-adrenal axis during pregnancy in rats bred for high anxiety-related behaviour. Psychoneuroendocrinology 23: 449-463.

Neumann ID, Wigger A, Torner L, Holsboer F, Landgraf R (2000a). Brain oxytocin inhibits basal and stress-induced activity of the hypothalamo-pituitary-adrenal axis in male and female rats: partial action within the paraventricular nucleus. J Neuroendocrinol 12: 235-243.

Neumann ID, Torner L, Wigger A (2000b). Brain oxytocin: differential inhibition of neuroendocrine stress responses and anxiety-related behaviour in virgin, pregnant and lactating rats. Neuroscience 95: 567-575.

Nijsen MJMA, Croiset G, Diamant M, De Wied D, Wiegant VM (2001). CRH signalling in the bed nucleus of the stria terminalis is involved in stress-induced cardiac vagal activation in conscious rats. Neuropsychopharmacology 24: 1-10.

Ohl F, Toschi N, Wigger A, Henniger MSH, Landgraf R (2001). Dimensions of emotionality in a rat model of innate anxiety. Behav Neurosci 115: 429-436.
Overstreet DH, Rezvani AH, Janowski DS (1992). Maudsley reactive and nonreactive rats differ only in some tasks reflecting emotionality. Physiol Behav 52: 149-152.

Paxinos G, Watson C (1998). The Rat Brain in Stereotaxic Coordinates. Academic Press: Sydney, Australia.

Pellow S, Chopin P, File SE, Briley M (1985). Validation of open: closed arms entries in an elevated plus-maze as a measure of anxiety in the rat. J Neurosci Methods 14: 149-167.

Pitkow LJ, Sharer CA, Ren X, Insel TR, Terwilliger EF, Young LJ (2001). Facilitation of affiliation and pair-bond formation by vasopressin receptor gene transfer into the ventral forebrain of a monogamous vole. J Neurosci 21: 7392-7396.

Plotsky P (1991). Pathways to the secretion of ACTH: a view from the portal. J Neuroendocrinol 3: 1-10.

Price ML, Curtis AL, Kirby LG, Valentino RJ, Lucki I (1998). Effects of corticotropin-releasing factor on brain serotonergic activity. Neuropsychopharmacology 18: 492-502.

Primus RJ, Yevich E, Baltazar C, Gallager DW (1997). Autoradiographic localization of CRF1 and CRF2 binding sites in adult rat brain. Neuropsychopharmacology 17: 308-316.

Raadsheer FC, Hoogendijk WJ, Stam FC, Tilders FJ, Swaab DF (1994). Increased numbers of corticotropin-releasing hormone expressing neurons in the hypothalamic paraventricular nucleus of depressed patients. Neuroendocrinology 60: 436-444.

Radulovic J, Fischer A, Katerkamp U, Spiess J (2000). Role of regional neurotransmitter receptors in corticotropin-releasing factor (CRF)-mediated modulation of fear conditioning. Neuropharmacology 39: 707-710.

Radulovic J, Ruhmann A, Liepold T, Spiess J (1999). Modulation of learning and anxiety by corticotropin-releasing factor (CRF) and stress: differential roles of CRF receptors 1 and 2. J Neurosci 19: 5016-5025.

Raggenbass M, Alberi S, Zaninetti M, Pierson P, Dreifuss JJ (1998). Vasopressin and oxytocin action in the brain: cellular neurophysiological studies. Prog Brain Res 119: 263-273.

Rivier C, Vale WW (1983). Interaction of corticotropin-releasing factor and arginine vasopressin on adrenocorticotropin secretion in vivo. Endocrinology 113: 939-942.

Salomé N, Viltart O, Darnaudéry M, Salchner P, Singewald N, Landgraf $\mathrm{R}$ et al (2002). Reliability of high and low anxietyrelated behavior; influence of laboratory environment and multifactorial analysis. Behav Brain Res 136: 227-237.

Sánchez MM, Young LJ, Plotsky PM, Insel TR (1999). Autoradiographic and in situ hybridization localization of corticotropinreleasing factor 1 and 2 receptors in non-human primate brain. $J$ Comp Neurol 408: 365-377.

Sánchez MM, Young LJ, Plotsky PM, Insel TR (2000). Distribution of corticosteroid receptors in the rhesus brain: relative absence of glucocorticoid receptors in the hippocampal formation. $J$ Neurosci 20: 4657-4668.

Sapolsky RM, McEwen BS (1985). Down-regulation of neural corticosterone receptors by corticosterone and dexamethasone. Brain Res 339: 161-165.

Skelton KH, Nemeroff CB, Knight DL, Owens MJ (2000). Chronic administration of the triazolobenzodiazepine alprazolam produces opposite effects on corticotropin-releasing factor and urocortin neuronal systems. J Neurosci 20: 1240-1248.

Steckler T, Holsboer F (1999). Corticotropin-releasing hormone receptor subtypes and emotion. Biol Psychiatry 46: 1480-1508.

Swanson LW, Sawchenko PE (1983). Hypothalamic integration: organization of the paraventricular and supraoptic nuclei. Ann Rev Neurosci 6: 269-324

Takahashi LK, Ho SP, Livanov V, Graciani N, Arneric SP (2001). Antagonism of $\mathrm{CRF}(2)$ receptors produces anxiolytic behavior in animal models of anxiety. Brain Res 902: 135-142.

Tazi A, Swerdlow NR, Le Moal M, Rivier J, Vale W, Koob GF (1987). Behavioral activation of CRF: evidence for the involvement of the ventral forebrain. Life Sci 41: 41-49. 
Umriukhin A, Wigger A, Singewald N, Landgraf R (2002). Hypothalamic and hippocampal release of serotonin in rats bred for hyper- or hypo-anxiety. Stress 5: 299-305.

van Gaalen MM, Stenzel Poore MP, Holsboer F, Steckler T (2002). Effects of transgenic overproduction of $\mathrm{CRH}$ on anxiety-like behaviour. Eur J Neurosci 15: 2007-2015.

Villar MJ, Meister B, Hokfelt T (1994). Reorganization of neural peptidergic systems in the median eminence after hypophysectomy. J Neurosci 14: 5996-6012.

Weiss F, Paulus MP, Lorang MT, Koob GF (1992). Increases in extracellular dopamine in the nucleus accumbens by cocaine are inversely related to basal levels: effects of acute and repeated administration. J Neurosci 12: 4372-4380.

Wigger A, Loerscher P, Weissenbacher P, Holsboer F, Landgraf R (2001). Cross-fostering and cross-breeding of HAB and LAB rats: a genetic rat model of anxiety. Behav Genet 31: 371-382.

Windle RJ, Shanks N, Lightman SL, Ingram CD (1997). Central oxytocin administration reduces stress-induced corticosterone release and anxiety behavior in rats. Endocrinology 138: 2829-2834.

Wotjak CT, Kubota M, Liebsch G, Montkowski A, Holsboer F, Neumann I et al (1996). Release of vasopressin within the rat paraventricular nucleus in response to emotional stress: a novel mechanism of regulating adrenocorticotropic hormone secretion? J Neurosci 16: 7725-7732.

Wotjak CT, Ludwig M, Ebner K, Russell JA, Singewald N, Landgraf $\mathrm{R}$ et al (2002). Vasopressin from hypothalamic magnocellular neurons has opposite actions at the adenohypophysis and in the supraoptic nucleus on ACTH secretion. Eur J Neurosci 16: 477-485.

Young LJ (2002). The neurobiology of social recognition, approach and avoidance. Biol Psychiatry 51: 18-26.

Young LJ, Toloczko D, Insel TR (1999). Localization of vasopressin (V1a) receptor binding and mRNA in the rhesus monkey brain. J Neuroendocrinol 11: 291-297.

Young LJ, Wang Z, Cooper TT, Albers HE (2000). Vasopressin (V1a) receptor binding, mRNA expression and transcriptional regulation by androgen in the Syrian hamster brain. J Neuroendocrinol 12: 1179-1185.

Young LJ, Winslow JT, Nilsen R, Insel TR (1997). Species differences in $\mathrm{V}_{1 \mathrm{a}}$ receptor gene expression in monogamous and nonmonogamous voles: behavioral consequences. Behav Neurosci 111: 599-605. 